\title{
Could vaping be a new weapon in the battle of the bulge?
}

Marewa Glover ${ }^{1} \mathrm{PhD}$, Bernhard H.Breier ${ }^{2} \mathrm{PhD}$, Linda Bauld ${ }^{3} \mathrm{PhD}$

1. School of Public Health, College of Health, Massey University, Private Bag 102904, North Shore, Auckland 0745, New Zealand, Telephone: 64272757 852,

M.Glover@massey.ac.nz

2. Massey Institute of Food Science and Technology, College of Health, Massey University, Private Bag 102904, North Shore, Auckland 0745, New Zealand

3. UK Centre for Tobacco and Alcohol Studies, University of Stirling, United Kingdom

\section{Abstract}

As the prevalence of tobacco smoking has been decreasing, obesity has increased.

Obesity is set to overtake tobacco smoking in many developed countries as the primary preventable cause of conditions such as diabetes, cancer and heart disease. Obesity is a complex condition that is challenging public health prevention efforts. Tobacco smoking mitigates weight gain through nicotine's effect on the brain and metabolism.

The prospect of gaining weight upon stopping smoking acts as an inhibitor to quitting and weight gain post-cessation is a common cause of relapse. Vaping nicotine is a new and controversial phenomenon that is highly attractive to smokers, but raises fears for health among public health and tobacco control advocates. There have been some reports among vapers that vaping is helping to mitigate weight gain after stopping smoking and or vaping is helping them to control their weight. There are several potential mechanisms by which vaping, in addition to the direct effects of nicotine, could facilitate weight control, these include taste perception, physical mouth feel and sensation and behavioural replacement. Research on the potential for vaping to support weight control may be worth pursuing given the human and economic costs of the global obesity epidemic and the failure of current obesity prevention strategies.

This is a pre-copyedited, author-produced PDF of an article accepted for publication in Nicotine \& Tobacco Research following peer review. The version of record 'Could Vaping be a New Weapon in the Battle of the Bulge?', Marewa Glover, Bernhard H Breier, Linda Bauld, Nicotine \& Tobacco Research, Volume 19, Issue 12, 7 November 2017, Pages 1536-1540 is available online at: https://doi.org/10.1093/ntr/ntw278 


\section{Introduction}

The top three leading causes of morbidity and mortality in virtually every country in the world are smoking, high blood pressure and obesity (1). Smoking tobacco is still the largest preventable cause of death and disease. An estimated 400 million adults worldwide will be killed by smoking between 2010 and 2050 (2). The obesity epidemic, however, is fast becoming one of the world's largest health problems with prevalence rates continuing to rise in developed nations $(1,3)$ despite experimentation with a range of policies and interventions.

Obesity is a complex condition (4) that increases an individual's risk of developing a range of non-communicable diseases including type-2 diabetes (T2D), cardiovascular disease (CVD) and several forms of cancer $(5,6)$. Current public health strategies to curb obesity focus on food and nutrition policies $(7,8)$, availability of and access to healthier food $(9,10)$ and community-based interventions (11). However, the conventional wisdom that we get fat solely because we consume more energy than we expend does not explain the substantial world-wide increase in obesity $(3,12)$. Furthermore, efforts to cure obesity by inducing a negative energy balance, through counselling people either to eat less or exercise more, are often ineffective because of numerous interconnected physiological, psychological, social and environmental factors (13). Progress in obesity management will require greater understanding of the biological, behavioural, and environmental factors associated with lifestyle changes (14, 15).

The use of electronic cigarettes (e-cigs) has been suggested as a possible method to combat obesity. The first modern e-cigs were commercialised in 2003 with the sole purpose of aiding smoking cessation. However, there may be a side effect of weight control for users. E-cigs create a vapour by heating nicotine that is suspended in a liquid of propylene glycol and glycerine. When inhaled the vapour provides the user with a 'smoking' sensation in their mouth and a throat 'hit' familiar to smokers. In addition, the associated physical actions of vaping such as lifting the device to the mouth, inhaling and exhaling a visible 'cloud', mimic actions strongly conditioned with smoking (16). The e-liquids used in e-cigs can be bought readymade or as base liquids that can be mixed with flavours to suit individual preferences for taste, vapour density, visibility and 
amount, sensation and nicotine concentration. There are literally thousands of e-liquid flavours on the global market. New vapers, who smoke or are switching from smoking tobacco, reportedly often start with tobacco flavours but later switch to fruit and other food-related flavours $(17,18)$.

In this article we ask two questions. First, could the use of e-cigs or nicotine vapourisers help appetite control, and second, could vaping assist with weight control. If vaping could influence either of these, it could play a supportive role in obesity prevention, particularly among smokers who stop using combustible tobacco and are at an increased risk of weight gain. In order to explore these two questions, however, it is first necessary to understand the links between: smoking, nicotine, appetite and weight regulation; and how taste, flavour and aroma perception may influence appetite and satiety or influence body weight. Understanding these mechanisms provides the background for future research that may address practical considerations about the potential role of vaping to achieve weight control, especially in smokers who are committed to cessation.

\section{Nicotine's influence on appetite regulation}

Smoking decreases appetite and smokers often report that they smoke to control their body weight (19). There is evidence that smoking is causally associated with lower body mass index (20) and cessation is frequently followed by rapid weight gain (21). Weight gain is a major deterrent to many smokers who want to quit $(19,22)$. Indeed, the significant increase in the prevalence of overweight and obesity in recent years has been attributed in part to decreases in smoking prevalence. One analysis suggests that up to $14 \%$ of the rise in obesity rates could be attributable to the concurrent drop in smoking, at least in the USA (23).

The effects of smoking on body weight are caused by the anorexic effect of nicotine in tobacco smoke, that is, nicotine decreases food intake (24). Recent studies on weight gain after cessation have identified two main pathways (24). The first involves central appetite regulatory mechanisms in the brain that are responsible for nicotine's appetite suppressing effect $(21,22)$. Nicotine activates nicotinic acetylcholine receptors located on pro-opiomelanocortin (POMC) neurons in the arcuate nucleus of the hypothalamus. 
POMC neurons stimulate several agonist and antagonist molecules that activate the melanocortin (MC) system involved in regulating food intake, effectively suppressing appetite and weight gain. Nicotine exerts its potent action via the brain MC system, and the weight gain associated with smoking cessation is due to a reduced activity of MC4 receptors, thus taking the brake off appetite control. The $\mathrm{MC}$ system plays a key role in the regulation of appetite and food intake.

The second pathway involves nicotine's effects on increasing energy expenditure and resting metabolic rate (19). Nicotine administration leads to an increase in the metabolic rate within minutes of smoking a cigarette (25) and, importantly, energy expenditure is reduced with smoking cessation $(19,25)$. Some of these changes could be modified with continued use of nicotine separate from tobacco smoking - through longer term use of nicotine replacement therapy, for example, or nicotine-containing e-cigs.

Other mechanisms that may contribute to weight gain after smoking cessation include the effects of nicotine on taste and brain reward systems $(26,27)$. Nicotine modifies taste responses (28), and the bitter taste of nicotine may influence food intake through a direct action on taste receptors and taste pathways (24). Nicotine also acts on the brain reward systems $(29,30)$, it influences food reinforcement and hedonic preference as well as palatability of food (31). Unfortunately, current pharmacological cessation therapies, such as varenicline and bupropion, have not been effective in controlling body weight (32). In addition, the plant alkaloid cytisine, a nicotinic agonist that has been used as a smoking cessation aid in Eastern Europe, does not alleviate post-cessation weight gain (33).

\section{Taste perception, food hedonics and obesity}

High levels of dietary sugars and fats are a main cause of obesity (34). Given that both sweetness and fat have a powerful hedonic appeal, preferences for sweet and fatty foods are important contributors to increases in body weight and metabolic disease risk $(35,36)$. For example, Ettinger, et al. (37) reported that overweight women had a higher detection threshold and lower perception of sweetness than normal weight groups, suggesting that overweight women may require higher concentrations to detect sweetness and may consume more sugar (38). Similar observations have been reported 
for fat taste perception, with low-sensitivity fat tasters, who have low oral-intensity perception of linoleic acid, inclined to consume more fat and having a higher body mass index than high-sensitivity fat tasters $(36,39)$.

The relationship between oral sensory hedonics and eating preference is well established and plays an important role in the design of foods with distinct consumer attributes (40). Recent studies suggest that an individual's sensitivity for a particular taste, flavour or aroma may be linked with specific food choices $(41,42)$ and may serve as a potential risk marker for metabolic disease (43-45).

\section{Taste perception, flavour and aroma influence satiety}

The role of sensory-specific satiety is attracting increasing attention in light of the continuing world-wide escalation of overweight and obesity (3). Sensitivity to sweet and fat taste varies considerably between individuals $(46,47)$. Preference for sweet and fat taste is acquired early in life as children learn to like flavours that are energy dense (48, 49). Several studies have reported positive associations between the preference for sweet and fat taste and the consumption of sugar- and fat-rich foods (43,50-52), and there is increasing interest in delineating the relationships between taste, flavour, aroma and satiety. These taste preferences may be important for vaping, where users can choose different flavours that could potentially address food cravings, as we explore further below.

Research that interrogates how taste and aroma enhance satiation will support the development of products that induce or increase the feeling of satiation while reducing food intake (53). Such approaches may exploit knowledge about enhanced sensory attributes generated through the smell, taste, colour, temperature and mouthfeel of food (54). In this respect, the role of taste perception and aroma as sensory triggers of satiety mechanisms show considerable promise (55). The proof of principle has been reported in several recent human studies demonstrating that the addition of capsaicin to a diet enhances anorexigenic sensations, including satiety and fullness (56). Interestingly, capsaicin in vaporisers has been found to reduce cravings to smoke, reduce negative affect associated with withdrawals and provide satisfaction possibly due to replication of respiratory tract sensations associated with smoking tobacco (57). The inclusion of 
capsaicin in vaping e-liquids could have a role in assisting weight control but welldesigned randomised controlled trials would need to assess this, and efficacy and possible modes of actions and mechanism of the observed effect need to be determined.

\section{Could vaping assist weight control?}

Within vaper's forums, the notion of vaping with or without nicotine, for weight control has arisen. Petitioners against vaping restrictions have also cited weight control as a potential benefit of vaping (58). Participants in a recent trial of vaping for smoking cessation did not report significant weight gain in the longer term (at one year post quit date) when compared with continuing smokers and reducers (59). In addition, only two participants cited appetite control as a main reason for initiating vaping in a large international survey, but more importantly 28 said vaping helped them control their weight/appetite; 37 said it helps with controlling weight and sugar cravings; 27 claimed they had experienced weight loss as a result of starting to vape; eight had increased weight; five experienced a decrease in their blood sugar levels (T2D) and three had reduced cholesterol levels (60).

\section{Could vaping assist appetite control?}

It is already established that nicotine has appetite suppressant actions in the MC system and assists glucose metabolism, as outlined above. It is also well known that some people practising dietary restraint may use smoking to attenuate food cravings. If vapour delivers similar or as effective levels of nicotine, these actions could be expected to be retained. Animal studies comparing the effects on weight following exposure to tobacco smoke and e-cig vapour generated conflicting results. One study using neonatal mice found reduced weight for both tobacco smoke and e-cig vapour (61) and another study reported that effects on body weight occurred only in the group exposed to tobacco smoke (62). Ritualistic behaviours, for example, mixing one's own liquids, putting the parts of the e-cig together (reminiscent of cigarette rolling), filling the e-cig and the act of vaping may, like smoking, also be used as an alternative to the act of eating. However, vaping could have unique properties in that the smell, taste and mouth feel created by flavoured vapour could play a role in mitigating food cravings. 
Vaping is not without risks, although evidence to date suggests that it is much safer than continued tobacco smoking $(63,64)$. Concerns have been expressed about the constituents of some flavourings although to date these have not been formally explored in trials with people. Trace or very low levels of toxic contaminants have been detected in some flavoured e-liquids with some studies suggesting that the level of diacetyl in particular e-liquids has potential to be harmful even when present at levels 100 times lower than in tobacco smoke (65). Questions also remain about long term use and potential health consequences, for example of the irritant effect of vapour on the respiratory system (66).

\section{Conclusion}

E-cigs may have promise for smoking cessation and could play a valuable role in reducing preventable deaths by contributing to reductions in smoking prevalence. Obesity is set to overtake tobacco smoking in many developed countries as the primary preventable cause of conditions such as diabetes, cancer and CVD. It is possible that ecigs could contribute to reductions in overweight and obesity alongside reducing smoking. More research on the potential of e-cigs to reduce disease risks is needed, and investigation of any potential role they may play in mitigating weight gain is a viable topic for future study.

Several lines of investigation are worth pursuing. First, studies with vapers should explore the perceived benefits in terms of weight control and document vaping use for this perceived purpose. Observational follow-up studies could usefully track if vaping 'weight-controllers' are all ex-smokers and whether they are hoping to mitigate postcessation weight gain, or whether there are any ex- or never smokers adopting vaping specifically for this purpose, and if so why? Further questions include whether nicotine is used in e-liquids and at what concentration and frequency? The existing known usefulness of nicotine for suppressing weight gain (67) plus vaper reports of e-cig use for weight control would suggest that the use of vaping with nicotine and without nicotine has to be formally tested in a randomised controlled trial. Trials of vaping for smoking cessation are presently occurring but there are no known registered trials of smoking cessation via vaping specifically for people who are overweight or obese and who are concerned about further weight gain. Further questions include: are particular flavours perceived to be more useful than others, and if so why? Furthermore, well-designed 
studies using human volunteers could formally test the effect of vaping specific e-liquids on satiety and investigate the role of taste, smell, sensation of inhaling vapour as well as the volume of vapour and mouth feel. Interestingly, some vapers perceive vegetable glycerine to be sweet, thus there is a need to test if appetite or food cravings vary in accordance with different proportions of vegetable glycerine to propylene glycol. If there is an effect of vaping on weight, is this effect only present in those quitting smoking or can it also be seen in those who are naïve to nicotine? Such questions could be explored in human laboratory experiments involving both smokers about to quit and never smokers.

Clearly, such research would not be without controversy. It could be considered unethical to introduce naive users to nicotine, a potentially dependency forming substance. Short-term nicotine vaping is unlikely to lead to nicotine dependency or tobacco smoking and should be sufficient to determine at what level an effect on appetite may be detected if at all. Vaping is not considered harmless even without nicotine (68), thus introducing current non-smokers to vaping even without nicotine could also be considered unethical. In addition, there is opposition to vaping among some public health researchers. Their alarm that smokers are switching to vaping, despite the estimated $95 \%$ lowered health risk (64) could increase at the thought of non-smokers being attracted to vaping for weight control if this concept begins to be discussed in the scientific or public realm. In the immediate term, therefore, the potential of vaping for weight control should be carefully explored in studies where e-cigs are used for smoking cessation. The research community, policy makers and the public need to be aware of the emerging perception that vaping may have potential benefit for appetite and weight control.

\section{Acknowledgements}

No funding was received to support this work. BHB is supported by the Health Research Council of New Zealand to perform research of new pathways to obesity prevention and metabolic health.

\section{Conflicts of Interest}

The authors have no competing financial interests in relation to the work. 


\section{References}

1. World Health Organisation. Obesity and overweight, Fact sheet №311. 2014 (updated May 2014); Available from:

http://www.who.int/mediacentre/factsheets/fs311/en/.

2. Jha P. Avoidable deaths from smoking: a global perspective. Public Health Rev. 2012;33:569-600.

3. Ng M, Fleming T, Robinson M, Thomson B, Graetz N, Margono C, et al. Global, regional, and national prevalence of overweight and obesity in children and adults during 1980-2013: a systematic analysis for the Global Burden of Disease Study 2013. Lancet. 2014 Aug 30;384(9945):766-81. doi: 10.1016/S0140-6736(14)60460-8.

4. Mori M, Higuchi K, Sakurai A, Tabara Y, Miki T, Nose H. Genetic basis of interindividual variability in the effects of exercise on the alleviation of lifestyle-related diseases. J Physiol. 2009 Dec 1;587(Pt 23):5577-84.

5. Huxley R, Mendis S, Zheleznyakov E, Reddy S, Chan J. Body mass index, waist circumference and waist:hip ratio as predictors of cardiovascular risk--a review of the literature. Eur J Clin Nutr. 2010 Jan;64(1):16-22.

6. Haslam DW, James WP. Obesity. Lancet. 2005 Oct 1;366(9492):1197-209.

7. Swinburn B, Sacks G, Vandevijvere S, Kumanyika S, Lobstein T, Neal B, et al. INFORMAS (International Network for Food and Obesity/non-communicable diseases Research, Monitoring and Action Support): overview and key principles. Obes Rev. 2013 Oct;14 Suppl 1:1-12.

8. Martin J, Peeters A, Honisett S, Mavoa H, Swinburn B, de Silva-Sanigorski A. Benchmarking government action for obesity prevention--an innovative advocacy strategy. Obes Res Clin Pract. 2014 Jul-Aug;8(4):e388-98.

9. Ni Mhurchu C, Eyles H, Schilling C, Yang Q, Kaye-Blake W, Genc M, Blakely T. Food prices and consumer demand: differences across income levels and ethnic groups. PLoS One. 2013;8(10):e75934.

10. Volkova E, Neal B, Rayner M, Swinburn B, Eyles H, Jiang Y, Michie J, Ni Mhurchu C. Effects of interpretive front-of-pack nutrition labels on food purchases: protocol for the Starlight randomised controlled trial. BMC Public Health. 2014;14(1):968. 11. Rush E, McLennan S, Obolonkin V, Vandal AC, Hamlin M, Simmons D, Graham D. Project Energize: whole-region primary school nutrition and physical activity 
programme; evaluation of body size and fitness 5 years after the randomised controlled trial. Br J Nutr. 2014 Jan 28;111(2):363-71.

12. Taubes $G$. The science of obesity: what do we really know about what makes us fat? An essay by Gary Taubes. BMJ. 2013;346:f1050.

13. Scheen AJ, Van Gaal LF. Combating the dual burden: therapeutic targeting of common pathways in obesity and type 2 diabetes. Lancet Diabetes Endocrinol. 2014 Nov;2(11):911-22. doi: 10.1016/S2213-8587(14)70004-X.

14. Hill JO. Understanding and addressing the epidemic of obesity: an energy balance perspective. Endocr Rev. 2006 Dec;27(7):750-61.

15. McGill A-T. Past and future corollaries of theories on causes of metabolic syndrome and obesity related co-morbidities part 2: a composite unifying theory review of human-specific co-adaptations to brain energy consumption. Arch Public Health. 2014;72(1):31.

16. Rose JE, Behm FM, Westman EC, Johnson M. Dissociating nicotine and nonnicotine components of cigarette smoking. Pharmacol Biochem Be. September 2000;67(1):71-81. doi.org/10.1016/S0091-3057(00)00301-4.

17. Polosa R, Capponnetto P, Cibella F, Le-Houezec J. (2015). Quit and smoking reduction rates in vape shops consumers: A prospective 12 month survey. Int $J$ Environ Res Public Health. 2015,12:3428-3438. doi:10.3390/ijerph120403428.

18. Farsalinos KE, Romagna G, Tsiapras D, Kyrzopoulos S, Spyrou A, Voudris V. Impact of Flavour Variability on Electronic Cigarette Use Experience: An Internet Survey. Int J Environ Res Public Health. 2013;10(12):7272-7282. doi:10.3390/ijerph10127272.

19. Cena H, Fonte ML, Turconi G. Relationship between smoking and metabolic syndrome. Nutr Rev. 2011 Dec;69(12):745-53.

20. Freathy RM, Kazeem GR, Morris RW, Johnson PCD, Paternoster L, Ebrahim S, et al. Genetic variation at CHRNA5-CHRNA3-CHRNB4 interacts with smoking status to influence body mass index. Int J Epidemiol 2011;1-12. doi:10.1093/ije/dyr077

21. Pistelli F, Aquilini F, Carrozzi L. Weight gain after smoking cessation. Monaldi Arch Chest Dis. 2009 Jun;71(2):81-7.

22. Seeley RJ, Sandoval DA. Neuroscience: weight loss through smoking. Nature. 2011 Jul 14;475(7355):176-7.

23. Courtemanche, $C$ et al. (2016) The effect of smoking on obesity: evidence from a randomized trial, Working Paper 21937, National Bureau of Economic Research, http://www.nber.org/papers/w21937 
24. Mineur YS, Abizaid A, Rao Y, Salas R, DiLeone RJ, Gundisch D, Diano S, De Biasi M, Horvath TL, Gao XB, Picciotto MR. Nicotine decreases food intake through activation of POMC neurons. Science. 2011 Jun 10;332(6035):1330-2.

25. Walker J, Collins LC, Nannini L, Stamford BA. Potentiating effects of cigarette smoking and moderate exercise on the thermic effect of a meal. Int $J$ Obes Relat Metab Disord. 1992 May;16(5):341-7.

26. Zoli M, Picciotto MR. Nicotinic regulation of energy homeostasis. Nicotine Tob Res 2012 Nov;14(11):1270-90.

27. Donny EC, Caggiula AR, Weaver MT, Levin ME, Sved AF. The reinforcementenhancing effects of nicotine: implications for the relationship between smoking, eating and weight. Physiol Behav. 2011 Jul 25;104(1):143-8.

28. Megerdichian CL, Rees VW, Wayne GF, Connolly GN. Internal tobacco industry research on olfactory and trigeminal nerve response to nicotine and other smoke components. Nicotine Tob Res. 2007 Nov;9(11):1119-29.

29. Ngolab J, Liu L, Zhao-Shea R, Gao G, Gardner PD, Tapper AR. Functional Upregulation of alpha4* Nicotinic Acetylcholine Receptors in VTA GABAergic Neurons Increases Sensitivity to Nicotine Reward. J Neurosci. 2015 Jun 3;35(22):8570-8.

30. Yuan M, Cross SJ, Loughlin SE, Leslie FM. Nicotine and the adolescent brain. $J$ Physiol. 2015 Aug 15;593(16):3397-412.

31. Epstein LH, Leddy JJ, Temple JL, Faith MS. Food reinforcement and eating: a multilevel analysis. Psychol Bull. 2007 Sep;133(5):884-906.

32. Stoops WW, Vansickel AR, Glaser PE, Rush CR. The influence of acute varenicline administration on smoking and eating behavior in humans. Pharmacol Biochem Behav. 2008 Nov;91(1):165-9.

33. Etter JF. Cytisine for smoking cessation: a literature review and a meta-analysis. Arch Intern Med. 2006 Aug 14-28;166(15):1553-9.

34. Te Morenga LA, Howatson AJ, Jones RM, Mann J. Dietary sugars and cardiometabolic risk: systematic review and meta-analyses of randomized controlled trials of the effects on blood pressure and lipids. Am J Clin Nutr. 2014 May 7;100(1):6579.

35. Laffitte A, Neiers F, Briand L. Functional roles of the sweet taste receptor in oral and extraoral tissues. Curr Opin Clin Nutr Metab Care. 2014 Jul;17(4):379-85. 
36. Martinez-Ruiz NR, Lopez-Diaz JA, Wall-Medrano A, Jimenez-Castro JA, Angulo O. Oral fat perception is related with body mass index, preference and consumption of high-fat foods. Physiol Behav. 2014 Apr 22;129:36-42.

37. Ettinger L, Duizer L, Caldwell T. Body fat, sweetness sensitivity, and preference: determining the relationship. Can J Diet Pract Res. 2012 Spring;73(1):45-8.

38. Sartor F, Donaldson LF, Markland DA, Loveday H, Jackson MJ, Kubis HP. Taste perception and implicit attitude toward sweet related to body mass index and soft drink supplementation. Appetite. 2011 Aug;57(1):237-46.

39. Stewart JE, Feinle-Bisset C, Golding M, Delahunty C, Clifton PM, Keast RS. Oral sensitivity to fatty acids, food consumption and BMI in human subjects. Br J Nutr. 2010 Jul;104(1):145-52.

40. Dalton M, Finlayson G. Psychobiological examination of liking and wanting for fat and sweet taste in trait binge eating females. Physiol Behav. 2014;136:128-134.

41. Dinehart ME, Hayes JE, Bartoshuk LM, Lanier SL, Duffy VB. Bitter taste markers explain variability in vegetable sweetness, bitterness, and intake. Physiol Behav. 2006;87(2):304-13.

42. Pepino MY, Mennella JA. Habituation to the pleasure elicited by sweetness in lean and obese women. Appetite. 2012;58(3):800-5.

43. Stewart JE, Keast RSJ. Recent fat intake modulates fat taste sensitivity in lean and overweight subjects. Int J Obes. 2012;36(6):834-42.

44. Keller KL, Liang LCH, Sakimura J, May D, van Belle C, Breen C, Driggin E, Tepper BJ, Lanzano PC, Deng L, Chung WK. Common Variants in the CD36 Gene Are Associated With Oral Fat Perception, Fat Preferences, and Obesity in African Americans. Obesity. 2012;20(5):1066-73.

45. Overberg J, Hummel T, Krude H, Wiegand S. Differences in taste sensitivity between obese and non-obese children and adolescents. Arch Dis Child. 2012 Dec;97(12):1048-52. doi: 10.1136/archdischild-2011-301189

46. Pepino MY, Finkbeiner S, Beauchamp GK, Mennella JA. Obese women have lower monosodium glutamate taste sensitivity and prefer higher concentrations than do normal-weight women. Obesity (Silver Spring). 2010 May;18(5):959-65.

47. Sartor F, Donaldson LF, Markland DA, Loveday H, Jackson MJ, Kubis H-P. Taste perception and implicit attitude toward sweet related to body mass index and soft drink supplementation. Appetite. 2011;57(1):237-46. 
48. Kern DL, McPhee L, Fisher J, Johnson S, Birch LL. The postingestive consequences of fat condition preferences for flavors associated with high dietary fat. Physiol Behav. 1993;54(1):71-6.

49. Ventura AK, Mennella JA. Innate and learned preferences for sweet taste during childhood. Curr Opin Clin Nutr Metab Care. 2011 Jul;14(4):379-84.

50. Mahar A, Duizer LM. The Effect of Frequency of Consumption of Artificial Sweeteners on Sweetness Liking by Women. J Food Sci. 2007;72(9):S714-S8.

51. Holt SHA, Cobiac L, Beaumont-Smith NE, Easton K, Best DJ. Dietary habits and the perception and liking of sweetness among Australian and Malaysian students: A cross-cultural study. Food Qual Prefer. 2000;11(4):299-312.

52. Acosta A, Hurtado MD, Gorbatyuk O, La Sala M, Duncan D, Aslanidi G, Campbell-Thompson M, Zhang L, Herzog H, Voutetakis A, Baum BJ, Zolotukhin S. Salivary PYY: A Putative Bypass to Satiety. PLoS ONE. 2011 10/10;6(10):e26137. 53. Ruijschop RM, Boelrijk AE, Burgering MJ, de Graaf C, Westerterp-Plantenga MS. Acute effects of complexity in aroma composition on satiation and food intake. Chem Senses. 2010 Feb;35(2):91-100.

54. Sorensen LB, Moller P, Flint A, Martens M, Raben A. Effect of sensory perception of foods on appetite and food intake: a review of studies on humans. Int J Obes Relat Metab Disord. 2003 Oct;27(10):1152-66.

55. Ruijschop RM, Boelrijk AE, de Ru JA, de Graaf C, Westerterp-Plantenga MS. Effects of retro-nasal aroma release on satiation. Br J Nutr. 2008 May;99(5):1140-8. 56. Janssens PL, Hursel R, Westerterp-Plantenga MS. Capsaicin increases sensation of fullness in energy balance, and decreases desire to eat after dinner in negative energy balance. Appetite. 2014 Jun;77:44-9.

57. Behm FM, Rose JE. Reducing craving for cigarettes while decreasing smoke intake using capsaicin-enhanced low tar cigarettes. Exp Clin Psychopharm. 1994;2(2):143-153. 58. Sumner HM, McQueen A, Scott MJ, Sumner W. Analysis of Comments in a Petition Defending Electronic Cigarettes Nicotine Tob Res first published online May 13, 2014 doi:10.1093/ntr/ntu055

59. Russo C, Cibella F, Caponnetto P, et al. Evaluation of Post Cessation Weight Gain in a 1-Year Randomized Smoking Cessation Trial of Electronic Cigarettes. Sci Rep. 2016;6:18763. doi:10.1038/srep18763.

60. Russell C. (2015). Vapers helping smokers. Powerpoint presentation. Paper in press. 
61. McGrath-Morrow SA, Hayashi M, Aherrera A, Lopez A, Malinina A, et al. The Effects of Electronic Cigarette Emissions on Systemic Cotinine Levels, Weight and Postnatal Lung Growth in Neonatal Mice. PLoS ONE. 2015;10(2):e0118344. doi:

10.1371/journal.pone.0118344.

62. Ponzoni, L Moretti, M Sala, M Fasoli, F Mucchietto, V Lucini, et al. Different physiological and behavioural effects of e-cigarette vapour and cigarette smoke in mice. Euro Neuropsychopharmacol. 2015; 25(10): 1775-1786.

http://dx.doi.org/10.1016/j.euroneuro.2015.06.010.

63. Nutt DJ, Phillips LD, Balfour D, et al. Estimating the harms of nicotine-containing products using the MCDA approach. Eur Addict Res. 2014;20:218-25.

64. Royal College of Physicians. (2016) Nicotine without smoke: tobacco harm reduction. Royal College of Physicians, London.

https://www.rcplondon.ac.uk/projects/outputs/nicotine-without-smoke-tobacco-harmreduction-0

65. Farsalinos KE, Kistler KA, Gillman G, Voudris V. Evaluation of electronic cigarette liquids and aerosol for the presence of selected inhalation toxins. Nicotine Tobacco Res2015;17(2):168-174 doi:10.1093/ntr/ntu176.

66. Campagna D, Cibella F, Caponnetto P, Amaradio MD, Caruso M, Morjaria JB, Malerba M, Polosa R. Changes in breathomics from a 1-year randomized smoking cessation trial of electronic cigarettes. Eur J Clin Invest. 2016;46(8):698-706.

67. Veldheer S, Yingst J, Zhu J, Foulds J. 10 year weight gain in smokers who quit, smokers who continued smoking and never smokers in the United States, nhanes 20032012. Int J Obesity. 2015;39(12):1727-32. doi: 10.1038/ijo.2015.127.

68. Pisinger $\mathrm{C}$. Why public health people are more worried than excited over ecigarettes. BMC Med. 2014;12:226. doi:10.1186/s12916-014-0226-y 